\title{
Use of Clavien-Dindo classification in evaluating complications following pancreaticoduodenectomy in 1,056 cases: A retrospective analysis from one single institution
}

\author{
WEI-GUO WANG ${ }^{1}$, SHAH RAM BABU ${ }^{2}$, LI WANG ${ }^{2}$, YANG CHEN $^{2}$, BO-LE TIAN ${ }^{2}$ and HONG-BO HE ${ }^{1}$ \\ Departments of ${ }^{1}$ Integrated Traditional Chinese and Western Medicine, and ${ }^{2}$ Pancreatic Surgery, \\ West China Hospital, Sichuan University, Chengdu, Sichuan 610041, P.R. China
}

Received January 21, 2017; Accepted March 16, 2018

DOI: $10.3892 / 01.2018 .8798$

\begin{abstract}
The Clavien-Dindo (C-D) classification is a simple and feasible grading system of postoperative complications. The aim of the present study was to apply this system to retrospectively classify all types of post-pancreaticoduodenectomy (PD) complications (PPCs) and to systematically identify associated risk factors. Between January 2009 and December 2014, the C-D classification was applied to retrospectively classify PPCs for 1,056 patients who had undergone PD at the West China Hospital. Univariate and multivariate analyses were performed to link perioperative parameters and mortality with the severity of PPCs, which were subdivided into overall PPCs (Grade I-V), severe PPCs (Grade III-V) and mortality (Grade V). The number of patients with Clavien-Dindo grade I, II, IIIa, IIIb, IVa, IVb and V complications was 185 (17.5\%), $128(12.1 \%), 50(4.7 \%), 25(2.4 \%), 35(3.3 \%), 19(1.8 \%)$ and $33(3.1 \%)$, respectively. A total of $475(45.0 \%)$ patients experienced overall PPCs; 168 (15.9\%) patients experienced severe PPCs; and 33 patients succumbed to mortality following PD. The following risk factors were identified following PD: Preoperative hypoproteinemia was correlated with all three subdivisions; obstructive jaundice was associated with severe PPCs and mortality; and older age was revealed to be an independent risk factor of mortality. A large retrospective study was performed in the present study and PD was correlated with a high occurrence of PPCs. The Clavien-Dindo system represents a broad applicable and feasible approach to evaluating
\end{abstract}

Correspondence to: Professor Bo-Le Tian, Department of Pancreatic Surgery, West China Hospital, Sichuan University, 37 Guo Xue Xiang, Chengdu, Sichuan 610041, P.R. China

E-mail: tianbole@qq.com

Dr Hong-Bo He, Department of Integrated Traditional Chinese and Western Medicine, West China Hospital, Sichuan University, 37 Guo Xue Xiang, Chengdu, Sichuan 610041, P.R. China

E-mail: hong-bo-he@qq.com

Key words: Clavien-Dindo classification, pancreaticoduodenectomy, risk factors, postoperative complication
PPCs in patients following PD. The independent risk factors of PPCs that were identified in the present study require further validation using the Clavien-Dindo classification in additional prospective studies.

\section{Introduction}

Pancreatoduodenectomy (PD) is the main surgical option for pancreatic neoplasms, duodenal neoplasms and other lesions located in the pancreatic head and periampullary region (1). Despite the prompt progress in surgical technologies and the persistent innovation of postoperative treatments over the last decades, post-pancreaticoduodenectomy complications (PPC) remain around 30-60\% (2-4), which may lead to several potential poor outcomes, including prolonged hospital stays, increased medical costs and mortality, all of which also affect pancreatic surgeons and researchers. Therefore, assessing outcomes and quality of PD has triggered interest in measuring and evaluating PPCs.

In most previous studies, various definitions and classifications were applied to access specific PPCs. For example, the International Study Group of Pancreatic Surgery (ISGPS) have formulated a series of generally acceptable, objective definitions and classifications for postoperative pancreatic fistula (POPF), post-pancreatectomy hemorrhage (PPH), and delayed gastric emptying (DGE) following PD from 2005 in order to facilitate objective and accurate comparison among different surgical experiences and diverse associated studies (5-7). These classifications have been widely used and favored by numerous studies $(3,8,9)$. However, there are a number of limitations to these classifications: i) They are only focused on specific PPCs, including PPH, POPF and DGE; ii) each system has complicated and unique assessment criteria for only one type of PPC and therefore, one type of classification is not applicable to others; and iii) synergistic efforts and risk factors cannot assessed among these diverse classifications $(10,11)$.

Owing to a lack of uniform classification, it is difficult and unfeasible to uniformly interpret various PPCs. In 1992, Clavien et al (12) established the Clavien-Dindo (C-D) classification, a simple and feasible grading system for all types of postoperative complications. The C-D classification system is characterized by a consistent therapy-oriented, 4-level 
severity grading, discriminating overall PPCs, and has been increasingly applied to evaluate surgical practices $(10,13,14)$. However, to the best of our knowledge, this grading system has not been used to evaluate PPCs in a large-sample cohort. Therefore, the present study applied this system to retrospectively classify all PPCs and systematically identify associated risk factors in our high-volume pancreatic center.

\section{Patients and methods}

Patients. All patients who underwent PD at West China Hospital (Sichuan, China) between January 2009 and December 2014 were included, comprising 660 males (62.5\%) and 396 females (37.5\%) with a mean age of $57.29 \pm 10.99$ (range, 18-88) years. All related data, including the patient characteristics, histopathology, surgical factors, postoperative treatments and outcomes, were collected from our database records and the electronic medical records of individual patients.

Operative technique. Each surgical team performed either open PD or laparoscopic PD in $>20$ cases annually according to the standards of the National Comprehensive Cancer Network (15). As the standard requirement of PD, the following organs were removed in the resection stage: Pylorus, distal antrum of the stomach, duodenum, pancreatic head, distal common bile duct, gallbladder and part of the jejunum. Vessel reconstruction was performed in patients who were investigated for segment or circumferential involvement of the superior mesenteric/portal vein or short segment extension to the superior mesenteric artery. Multivisceral resections were performed in patients who were investigated for adjacent organ invasion, including colon, liver, small bowel, spleen and kidney. In the reconstruction stage, pancreatic remnant was uniformly reconstructed by pancreatojejunostomy over an internal pancreatic stent or external pancreatic drainage according to the preference of the surgeon. Either classical Child type or isolated Roux-en-Y type of reconstruction was selected according to patient features during surgery.

Perioperative interventions and treatments. Preoperative evaluation of general condition was assessed by preoperative routine chest X-ray, electrocardiogram, laboratory tests and respiratory function tests. All patients routinely received perioperative antibiotic (Cefoxitin $1 \mathrm{~g}$, Cefmetazole $1 \mathrm{~g}$ or Cefuroxime $1 \mathrm{~g}$; intravenous drip) prophylaxis $1 \mathrm{~h}$ prior to surgery and every $3 \mathrm{~h}$ during surgery. Routine biochemical blood tests were measured every 2-3 days after surgery, or more often in the presence of PPCs. Ultrasonography or computed tomography scans were performed every 1-2 weeks according to postoperative features. As POPF is considered to be a common PPC, pancreatic amylase activity of abdominal drainage secretions was routinely investigated every 2-3 days from the third postoperative day (POD). Patients also underwent preventative postoperative somatostatin injection (Stilamin, Merck Serono Corp.; $12 \mathrm{mg} /$ day) if they had complication-associated factors, including advanced age, diabetes and soft pancreatic remnant.

Complications. The inpatient and outpatient medical records for each included patient were reviewed to identify various PPCs from the standard recovery, including the following local complications: POPF, PPH, intra-abdominal infection, incision complication, DGE, biliary fistula, intestinal obstruction, intestinal fistula, chylous fistula and acute pancreatitis; and the following systemic complications: Pulmonary complication, sepsis, cardiac complication and deep venous thrombosis.

PPH and POPF were defined according to the ISGPS criterion $(4,7)$. DGE was defined according to the Johns Hopkins definitions (16). Rare complications were defined as those with an incidence of $<1 \%$ of all the included patients. All complications were defined according to the Clavien-Dindo classification (12). Mortality was defined as any patients who succumbed over a 60-day hospital stay, regardless of cause. These were graded into overall complications (Grade I-V), severe complications (Grade III-V) and mortality (Grade V) based on the PPC-related intervention (e.g., medical treatment or an invasive intervention) or mortality.

Statistical analysis. Table I presents the descriptive statistics of basic characteristics and surgical details. Table II presents the inter-grade differences of each PPPC which were compared with rare complications using the Ridit test. Table III presents univariate analysis of risk factors of all C-D classification. Normally distributed variables are reported as the mean and standard deviation and compared using Student's t-tests. Non-normally distributed variables are expressed as the median (range) and were compared by Mann-Whitney U-tests. Categorical data were compared using $\chi^{2}$ test, with Yates continuity correction in a two-way contingency table, or Fisher's exact test. Additionally, Table IV presents multivariate analysis, which included the potential factors with $\mathrm{P} \leq 0.05$ in univariate analysis. And it was analyzed by binary logistic regression with conditional backward selection of potential factors. The results of the multivariate logistic regression analysis are expressed using P-values, odds ratios (ORs) and 95\% confidence intervals (CIs). All statistical analyses were performed using IBM SPSS Version 22 (IBM Corp., Armonk, NY, USA). P $\leq 0.05$ was considered to indicate a statistically significant difference.

\section{Results}

Patient characteristics and surgical details. All basic patient characteristics and surgical details are summarized in Table I. Patient preoperative conditions included the following: 380 (35.4\%) smokers, 223 (21.1\%) with diabetes, 167 (15.6\%) with alcohol abuse and 127 (12.1\%) with chronic pancreatitis. A total of $122(11.6 \%)$ patients underwent preoperative biliary drainage. According to the pathological observations, periampullary adenocarcinoma was identified as the major subtype (522 patients, 49.4\%), followed by pancreatic ductal adenocarcinoma with $32.9 \%$ (347 patients).

The majority of patients underwent open PD (1,016 patients, 96.2\%) and 40 (3.8\%) patients underwent laparoscopic PD. During surgery, $319(29.7 \%)$ patients were transfused with $1.56 \pm 18.52$ units of blood on average. There were 105 (9.9\%) vessel reconstructions and 44 (4.2\%) multivisceral resections, which included colon (13 cases, $1.2 \%$ ), liver (11 cases, $1.0 \%$ ), small bowel ( 9 cases, $0.9 \%$ ), spleen ( 4 cases, $0.4 \%$ ) and kidney ( 8 cases, $0.8 \%$ ). The mean postoperative hospital stay of all patients was $16.22 \pm 10.87$ days. Pancreatic texture, tumor size, size of pancreatic duct and details of transfusion are presented in Table I. 
Table I. Demographic characteristics, and pathological and surgical details of all patients.

\begin{tabular}{|c|c|}
\hline Variable & Value \\
\hline Total & $1,056(100)$ \\
\hline \multicolumn{2}{|l|}{ Sex } \\
\hline Male & $660(62.5)$ \\
\hline Female & $396(37.5)$ \\
\hline Age, years & $57.29 \pm 10.99$ \\
\hline \multicolumn{2}{|l|}{ Preoperative factors } \\
\hline Smoking & $380(35.4)$ \\
\hline Diabetes & $223(21.1)$ \\
\hline Alcohol abuse & $167(15.6)$ \\
\hline Chronic pancreatitis & $127(12.0)$ \\
\hline Total bilirubin, mmol/1 & $125.00 \pm 122.09$ \\
\hline Hemoglobin, g/l & $121.50 \pm 20.29$ \\
\hline Serum albumin, $\mathrm{g} / \mathrm{l}$ & $38.19 \pm 5.43$ \\
\hline CA19-9, U/1 & $247.65 \pm 327.40$ \\
\hline Preoperative biliary drainage & $122(11.6)$ \\
\hline \multicolumn{2}{|l|}{ ASA grade } \\
\hline $\mathrm{I}$ & $593(56.2)$ \\
\hline II & $318(30.1)$ \\
\hline III & $145(13.7)$ \\
\hline \multicolumn{2}{|l|}{ Histopathology } \\
\hline Pancreatic ductal adenocarcinoma & $347(32.9)$ \\
\hline Periampullary adenocarcinoma & $522(49.4)$ \\
\hline Chronic pancreatitis & $45(4.3)$ \\
\hline Other pancreatic neoplasms & $91(8.6)$ \\
\hline Other & $51(4.8)$ \\
\hline \multicolumn{2}{|l|}{ Pancreas texture } \\
\hline Soft & $548(51.9)$ \\
\hline Firm & $508(48.1)$ \\
\hline Tumor size, $\mathrm{cm}$ & $3.31 \pm 1.77$ \\
\hline \multicolumn{2}{|l|}{ Size of pancreatic duct, $\mathrm{mm}$} \\
\hline$\leq 3$ & $347(32.9)$ \\
\hline$<3$ & $709(67.1)$ \\
\hline Intraoperative transfusions & $1.56 \pm 18.51$ \\
\hline Intraoperative transfused patients & 319 (29.7) \\
\hline Total transfusions & $3.49 \pm 22.79$ \\
\hline Laparoscopic PD & $40(3.8)$ \\
\hline Vessel reconstruction & $105(9.9)$ \\
\hline Multivisceral resection & $44(4.2)$ \\
\hline Colon & $13(1.2)$ \\
\hline Spleen & $4(0.4)$ \\
\hline Liver & $11(1.1)$ \\
\hline Small bowel & $9(0.9)$ \\
\hline Kidney & $8(0.8)$ \\
\hline Postoperative hospital stay, days & $16.22 \pm 10.87$ \\
\hline
\end{tabular}

Data are presented as $\mathrm{n}(\%)$ or as the mean \pm standard deviation. CA19-9, cancer antigen 19-9; ASA, American Society of Anesthesiologists; PD, pancreaticoduodenectomy.
Postoperative complications. Of all the included patients, 475 (45.0\%) developed complications. Over time, the incidence of complications gradually decreased from $47.4 \%$ in 2009 to $44.0 \%$ in 2014. All postoperative complications are summarized in Table II. POPF, a major complication, occurred in 264 (25.0\%) patients. Pulmonary complications, which occurred in $93(8.8 \%)$ patients, were identified as the major systemic complication. There were 6 types of complication with rare incidences $(<1 \%$ of the included patients), including biliary fistula, intestinal obstruction, chylous fistula, deep venous thrombosis, intestinal fistula and acute pancreatitis.

According to the C-D classification, all patients with complications were identified as having the following grades of disease: $185(17.5 \%)$, grade I; $128(12.1 \%)$, grade II; 50 (4.7\%), grade IIIa; 25 (2.4\%), grade IIIb; 35 (3.3\%), grade IVa; 19 (1.8\%), grade IVb; and $33(3.1 \%)$, grade V. Compared with biliary fistula (incidence, $<1 \%$ of all the included patients), the C-D classification identified the differences in severity, and the differences between disease grades as being significant $(\mathrm{P}<0.05$, Table II). With regards to disease grades, patients with grade II or higher disease, excluding grade V disease, which resulted in patient mortality, had significantly longer postoperative hospital stays than those with grade 0 or I disease $(\mathrm{P}<0.05$; Fig. 1).

Risk factors for complications. Univariate and multivariate analyses of risk factors for PPCs were divided into three parts according to the severity of the C-D grade: Overall complications (Grade I-V), severe complications (Grade III-V) and mortality (Grade V; Tables III and IV).

The results of univariate analyses are presented in Table III. The overall complications (Grade I-V) were significantly associated with chronic pancreatitis $(\mathrm{P}=0.022)$, serum albumin $(\mathrm{P}=0.048)$, laparoscopic $\mathrm{PD}(\mathrm{P}=0.014)$ and intraoperative transfusions $(\mathrm{P}=0.001)$. Severe complications (Grade III-V) were revealed to be associated with an age $\geq 75$ years $(\mathrm{P}=0.035)$, diabetes $(\mathrm{P}=0.010)$, total bilirubin $(\mathrm{P}=0.008)$, serum albumin $(\mathrm{P}=0.034)$, hemoglobin $(\mathrm{P}=0.001)$ and intraoperative transfusions $(\mathrm{P}=0.001)$. Mortality (Grade $\mathrm{V})$, was associated with an age $\geq 75$ years $(\mathrm{P}<0.001)$, total bilirubin $(\mathrm{P}=0.019)$, serum albumin $(\mathrm{P}=0.019)$, hemoglobin $(\mathrm{P}=0.004)$ and intraoperative transfusions $(\mathrm{P}=0.038)$.

Table IV demonstrates the results of multivariate analyses. In terms of overall complications (Grade I-V), the incidence was proven to be associated with lower preoperative serum albumin ( $\mathrm{P}=0.016$; OR, 1.475; 95\% CI, 1.073-1.978). Severe complications (Grade III-V) were revealed to be associated with lower serum albumin $(\mathrm{P}=0.009$; OR, 1.623; 95\% CI, 1.130-2.332) and higher total bilirubin $(\mathrm{P}=0.048$; OR, $1.443 ; 95 \% \mathrm{CI}$, 1.004-2.073). With regards to mortality (Grade V), an age $\geq 75$ years $(\mathrm{P}=0.000$; OR, 5.860; 95\% CI, 2.321-14.979), lower serum albumin $(\mathrm{P}=0.034$; OR, 2.191; 95\% CI, 1.063-4.516) and higher total bilirubin $(\mathrm{P}=0.042$; OR, 2.017; 95\% CI, 1.849-4.789) were identified as independent risk factors.

\section{Discussion}

The present large sample cohort study was conducted to retrospectively analyze PPCs at West China Hospital. The C-D grading consistently classifies all types of PPCs 
Table II. Characteristics of Clavien-Dindo classification of all post-pancreaticoduodenectomy complications.

\begin{tabular}{|c|c|c|c|c|c|c|c|c|c|c|c|c|c|c|c|c|c|}
\hline \multirow[b]{2}{*}{ Complications } & \multicolumn{2}{|c|}{ Total } & \multicolumn{2}{|c|}{ Grade I } & \multicolumn{2}{|c|}{ Grade II } & \multicolumn{2}{|c|}{$\begin{array}{l}\text { Grade } \\
\text { IIIa }\end{array}$} & \multicolumn{2}{|c|}{$\begin{array}{l}\text { Grade } \\
\text { IIIb }\end{array}$} & \multicolumn{2}{|c|}{$\begin{array}{c}\text { Grade } \\
\text { IVa }\end{array}$} & \multicolumn{2}{|c|}{$\begin{array}{l}\text { Grade } \\
\mathrm{IVb}\end{array}$} & \multicolumn{2}{|c|}{ Grade V } & \multirow[b]{2}{*}{ P-value } \\
\hline & $\mathrm{N}$ & $\%$ & $\mathrm{~N}$ & $\%$ & $\mathrm{~N}$ & $\%$ & $\mathrm{~N}$ & $\%$ & $\mathrm{~N}$ & $\%$ & $\mathrm{~N}$ & $\%$ & $\mathrm{~N}$ & $\%$ & $\mathrm{~N}$ & $\%$ & \\
\hline Total & 475 & 45.0 & 185 & 17.5 & 128 & 12.1 & 50 & 4.7 & 25 & 2.4 & 35 & 3.3 & 19 & 1.8 & 33 & 3.1 & \\
\hline POPF & 264 & 25.0 & 143 & 54.2 & 46 & 17.4 & 30 & 11.4 & 7 & 2.7 & 17 & 6.4 & 10 & 3.8 & 11 & 4.2 & 0.000 \\
\hline Intra-abdominal infection & 88 & 8.3 & 6 & 6.8 & 27 & 30.7 & 27 & 30.7 & 3 & 3.4 & 12 & 13.6 & 8 & 9.1 & 5 & 5.7 & 0.000 \\
\hline Incision complication & 87 & 8.2 & 36 & 41.4 & 13 & 14.9 & 13 & 14.9 & 10 & 11.5 & 10 & 11.5 & 4 & 4.6 & 1 & 1.1 & 0.000 \\
\hline Pulmonary complication & 93 & 8.8 & 1 & 1.1 & 31 & 33.3 & 10 & 10.8 & 3 & 3.2 & 18 & 19.4 & 14 & 15.1 & 16 & 17.2 & 0.000 \\
\hline $\mathrm{PPH}$ & 78 & 7.4 & 0 & 0.0 & 14 & 17.9 & 14 & 17.9 & 12 & 15.4 & 15 & 15.4 & 6 & 7.7 & 17 & 21.8 & 0.000 \\
\hline Delayed gastric e & 30 & 2.8 & 1 & 3.3 & 23 & 76.7 & 2 & 6.7 & 0 & 0.0 & 1 & 3.3 & 2 & 6.7 & 1 & 3.3 & 0.021 \\
\hline Sepsis & 26 & 2.5 & 0 & 0.0 & 4 & 15.4 & 0 & 0.0 & 0 & 0.0 & 5 & 19.2 & 5 & 19.2 & 12 & 46.2 & 0.004 \\
\hline Renal complication & 22 & 2.1 & 0 & 0.0 & 2 & 9.1 & 0 & 0.0 & 1 & 4.5 & 0 & 0.0 & 3 & 13.6 & 16 & 72.7 & 0.014 \\
\hline Heart complication & 15 & 1.4 & 2 & 13.3 & 5 & 33.3 & 0 & 0.0 & 0 & 0.0 & 2 & 13.3 & 5 & 33.3 & 1 & 6.7 & 0.317 \\
\hline Biliary fistula & 9 & 0.9 & 4 & 44.4 & 3 & 33.3 & 2 & 22.2 & 0 & 0.0 & 0 & 0.0 & 0 & 0.0 & 0 & 0.0 & 1.000 \\
\hline Intestinal obstruction & 9 & 0.9 & 0 & 0.0 & 2 & 22.2 & 0 & 0.0 & 5 & 55.6 & 1 & 11.1 & 0 & 0.0 & 1 & 11.1 & 0.690 \\
\hline Chylous fistula & 7 & 0.7 & 4 & 57.1 & 2 & 28.6 & 1 & 14.3 & 0 & 0.0 & 0 & 0.0 & 0 & 0.0 & 0 & 0.0 & 0.831 \\
\hline Deep venous thrombosis & 5 & 0.5 & 0 & 0.0 & 2 & 40.0 & 0 & 0.0 & 0 & 0.0 & 1 & 20.0 & 0 & 0.0 & 2 & 40.0 & 0.925 \\
\hline Intestinal fistula & 2 & 0.2 & 0 & 0.0 & 1 & 50.0 & 1 & 50.0 & 0 & 0.0 & 0 & 0.0 & 0 & 0.0 & 0 & 0.0 & 0.609 \\
\hline Acute pancreatitis & 2 & 0.2 & 0 & 0.0 & 1 & 50.0 & 1 & 50.0 & 0 & 0.0 & 0 & 0.0 & 0 & 0.0 & 0 & 0.0 & 0.609 \\
\hline
\end{tabular}

$\mathrm{PPH}$, postpancreatectomy hemorrhage; POPF, postoperative pancreatic fistula.

Table III. Univariate analysis of risk factors in the Clavien-Dindo classification.

\begin{tabular}{|c|c|c|c|c|c|c|}
\hline \multirow[b]{2}{*}{ Univariate analysis } & \multicolumn{2}{|c|}{$\begin{array}{l}\text { Overall complication } \\
\quad(\text { Grade I-V })\end{array}$} & \multicolumn{2}{|c|}{$\begin{array}{l}\text { Severe complication } \\
\quad(\text { Grade III-V) }\end{array}$} & \multicolumn{2}{|c|}{ Mortality (Grade V) } \\
\hline & Value & $\mathrm{P}$-value & Value & $\mathrm{P}$-value & Value & $\mathrm{P}$-value \\
\hline Total & $475(45.0)$ & & $168(15.9)$ & & $33(3.1)$ & \\
\hline Age, years & & 0.129 & & 0.035 & & 0.000 \\
\hline$<75$ & $449(94.5)$ & & $155(92.3)$ & & $26(78.8)$ & \\
\hline$\geq 75$ & $26(5.5)$ & & $13(7.7)$ & & $7(21.2)$ & \\
\hline Sex & & 0.848 & & 0.139 & & 0.856 \\
\hline Male & $295(62.1)$ & & $114(67.9)$ & & $20(60.6)$ & \\
\hline Female & $180(37.9)$ & & $54(32.1)$ & & $13(39.4)$ & \\
\hline Diabetes & $99(20.8)$ & 0.880 & $23(13.7)$ & 0.010 & $7(21.2)$ & 1.000 \\
\hline Chronic pancreatitis & $45(9.5)$ & 0.022 & $15(8.9)$ & 0.197 & $3(9.1)$ & 0.598 \\
\hline Total bilirubin, mmol/l & $123.66 \pm 130.03$ & 0.102 & $160.29 \pm 142.48$ & 0.008 & $173.40 \pm 119.13$ & 0.019 \\
\hline Serum albumin, g/l & $34.90 \pm 5.49$ & 0.048 & $34.43 \pm 5.32$ & 0.034 & $33.06 \pm 4.88$ & 0.019 \\
\hline Hemoglobin, g/l & $121.11 \pm 21.00$ & 0.056 & $120.20 \pm 21.13$ & 0.001 & $114.64 \pm 18.86$ & 0.004 \\
\hline CA19-9, U/1 & $238.90 \pm 327.39$ & 0.055 & $302.32 \pm 363.10$ & 0.097 & $373.28 \pm 393.79$ & 0.469 \\
\hline Preoperative biliary drainage & $58(12.2)$ & 0.563 & $12(7.1)$ & 0.640 & $3(9.1)$ & 0.653 \\
\hline Laparoscopic PD & $26(5.5)$ & 0.014 & $8(6.4)$ & 0.507 & $1(3.0)$ & 0.817 \\
\hline Intraoperative transfusions & $1.31 \pm 3.36$ & 0.001 & $1.81 \pm 5.10$ & 0.001 & $1.76 \pm 2.31$ & 0.038 \\
\hline Vessel reconstruction & $43(9.1)$ & 0.409 & $14(8.3)$ & 0.573 & $4(12.1)$ & 0.671 \\
\hline Total multivisceral resection & $23(4.8)$ & 0.355 & $10(6.0)$ & 0.208 & $3(9.1)$ & 0.150 \\
\hline
\end{tabular}

CA19-9, cancer antigen 19-9; PD, pancreaticoduodenectomy. 
Table IV. Multivariate analysis of characteristics in the Clavien-Dindo classification.

$95 \%$ confidence interval

\begin{tabular}{|c|c|c|c|c|}
\hline \multirow{2}{*}{ Characteristic } & \multirow[b]{2}{*}{ P-value } & \multirow{2}{*}{ Odds ratio } & \\
\hline & & & Lower & Upper \\
\hline \multicolumn{5}{|c|}{ Overall complications (Grade I-V) } \\
\hline Serum albumin, $g / 1$ & 0.016 & 1.475 & 1.073 & 1.978 \\
\hline Cancer antigen 19-9, U/1 & 0.055 & 0.745 & 0.577 & 1.063 \\
\hline Hemoglobin, g/l & 0.053 & 0.762 & 0.579 & 1.003 \\
\hline Intraoperative transfusions & 0.067 & 0.611 & 0.225 & 1.119 \\
\hline \multicolumn{5}{|c|}{ Severe complications (Grade III-V) } \\
\hline Serum albumin, $\mathrm{g} / \mathrm{l}$ & 0.009 & 1.623 & 1.130 & 2.332 \\
\hline Total bilirubin, $\mathrm{mmol} / \mathrm{l}$ & 0.048 & 1.443 & 1.004 & 2.073 \\
\hline Intraoperative transfusions & 0.052 & 0.526 & 0.720 & 1.677 \\
\hline \multicolumn{5}{|l|}{ Mortality (Grade V) } \\
\hline Age $\geq 75$ years & 0.000 & 5.860 & 2.321 & 14.979 \\
\hline Serum albumin, $\mathrm{g} / \mathrm{l}$ & 0.034 & 2.191 & 1.063 & 4.516 \\
\hline Total bilirubin, $\mathrm{mmol} / \mathrm{l}$ & 0.042 & 2.017 & 1.849 & 4.789 \\
\hline
\end{tabular}

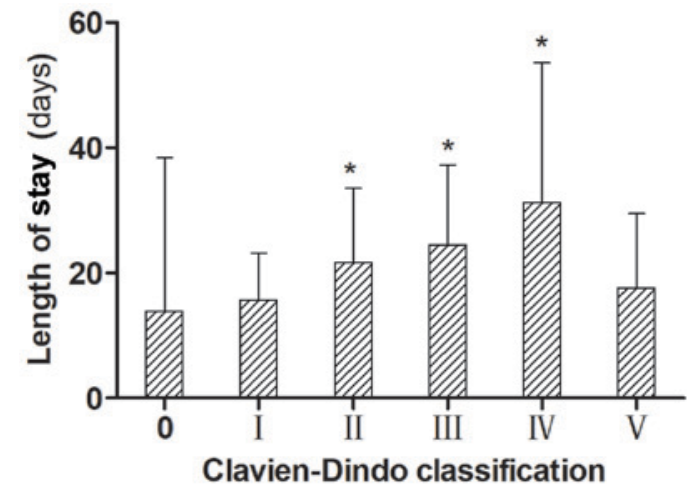

Figure 1. Postoperative hospital stays stratified by Clavien-Dindo grades. The mean postoperative hospital stay of all patients was $16.22 \pm 10.87$ days. From grade 0 to IV disease, the mean postoperative hospital stay increased with the grades $(13.85 \pm 24.54,15.78 \pm 7.39,21.67 \pm 11.86,24.51 \pm 12.70$ and $31.33 \pm 22.18$, respectively), except grade V (17.68 \pm 11.79$)$. Data are expressed as the mean \pm standard deviation. Patients with grade II, III and IV disease had significantly longer postoperative hospital stays, compared with patients with grade 0 or I disease $\left({ }^{*} \mathrm{P}<0.05\right)$.

with uniform and feasible criteria, whether postoperative therapy is required and which type of therapy is applied. Furthermore, these criteria have been applied to evaluate postoperative complications in a number of different surgical fields (17-19). Therefore, its advantage is to respectively systematically analyze all risk factors associated with PPCs and to affect the final outcomes of PD. In the present study, certain independent risk factors were confirmed on the basis of the PPC-related intervention.

Due to the fact that serum albumin is produced in the liver and normally forms $\sim 50 \%$ of human plasma protein with unique functions of oncotic pressure maintaining, transportation and inflammatory reaction. Hypoproteinemia, a very common condition in preoperative laboratory tests of PD, has been identified as a reliable indicator of the nutritional status of a patient (20). However, this is easily ignored by pancreatic surgeons, particularly modest hypoproteinemia (serum albumin $\leq 30$ and $\leq 35 \mathrm{mg} / \mathrm{l}$ ). In the present study, preoperative hypoproteinemia was correlated with PPCs, which was supported by a previous American retrospective study in 108,898 patients who underwent colorectal surgery (21). The latter study evaluated the association between modest hypoproteinemia and postoperative morbidity, and revealed that patients with preoperative hypoproteinemia exhibited a higher incidence of hospitalization for $>30$ days, unplanned intubation and wound disruption (21). Clinically, postoperative administration of human albumin is routinely infused to patients with hypoproteinemia following major abdominal surgery. However, persistent consumption, postoperative fasting, surgical trauma and development of PPCs occlude the extravascular deficiency of serum albumin and worsen the nutritional status of the patient. Therefore, preoperative hypoproteinemia requires consideration and necessary treatments to be administered, which means not only raising the preoperative serum albumin level, but also comprehensively improving the preoperative nutritional status of the patients in order to improve their surgical recovery.

Owing to cholestasis from biliary obstruction, obstructive jaundice is a common clinical manifestation for diseases at the pancreatic head and periampullary region. Cholestasis also causes endotoxemia, impairs immune responses and suppresses intravascular coagulation of blood cells, which was believed to worsen the early outcomes of patients following pancreatic surgery (22). These conclusions were also supported by the results of the present study, which demonstrated that jaundice increased the incidences of severe complications (grade III-V) and mortality (grade V) following PD. However, the outcomes of PD were not proven to benefit from preoperative biliary drainage, a common palliative intervention for jaundice, in the present study. This inconsistent correlation was also reported by a multicenter prospective randomized study in 202 patients with pancreatic cancer (23). It was explained that routine preoperative 
biliary drainage is associated with a relatively high incidence of technical failure and technical complications, particularly drainage occlusion and cholangitis (23). Therefore, routine preoperative biliary drainage does not benefit patients with obstructive jaundice who will undergo surgery $(23,24)$. In addition, the exact mechanisms by which jaundice increases PPCs and the value of preoperative biliary drainage require validation in additional studies (25).

With the gradually increasing number of older patients being considered for PD, the correlation between advanced age and PPCs has received attention from patients and surgeons. The results of the present study demonstrated that older patients (age, $\geq 75$ years) exhibited a higher rate of mortality. However, this result requires confirmation. Older patients were reported to have similar morbidity and mortality rates than younger patients by an American retrospective study in 727 patients undergoing PD (26). By contrast, another study enrolled 3,736 patients to determine age-dependent short-term outcomes following pancreatic resection by bivariate and multivariate analyses (27). Older patients exhibited a significantly higher in-hospital mortality rate than younger patients (11.4 vs. 2.4\%). They are also more likely to require care at an inpatient nursing or acute care facility at the time of discharge. Therefore, this result reminds pancreatic surgeons to cautiously recommend $\mathrm{PD}$ for older patients and to pay more attention to older patients with PPCs.

There are certain limitations to the present study. To begin with, long-term outcomes of pancreaticoduodenectomy were not evaluated in the present study. Additionally, the results of the present study were limited by the inherent defects of retrospective analysis, including information bias and selection bias. In the present study, however, all types of PPCs were evaluated as the uniform C-D classification. Univariate and multivariate analyses were performed in order to obtain reliable results. However, a further large-scaled, prospective study is required to evaluate the results of the present study and to obtain more valuable results.

A large retrospective study was performed in the present study and PD is correlated with a high occurrence of PPCs. The Clavien-Dindo system represents a widely applicable and feasible system for evaluating PPCs in patients following PD. The independent risk factors of PPCs that were identified in the present study require further validation using the Clavien-Dindo classification in further prospective studies.

\section{Acknowledgements}

Not applicable.

\section{Funding}

The present study was supported by the scientific research fund of the Science and Technology Department of Chengdu (grant no. 2014-HM01-00290-SF).

\section{Availability of data and materials}

The datasets used and/or analyzed during the current study are available from the corresponding author on reasonable request.

\section{Authors' contributions}

BLT designed the present study, YC and WGW conducted the majority of the experimentation, SRB and LW collected the data and edited the manuscript, WGW and YC analyzed data, and WGW drafted the manuscript. BLT and HBH interpreted the results and offered intellectual contribution to the manuscript.

\section{Ethics approval and consent to participate}

Not applicable.

\section{Consent for publication}

Not applicable.

\section{Competing interests}

The authors declare that they have no competing interests.

\section{References}

1. Senda Y, Shimizu Y, Natsume S, Ito S, Komori K, Abe T, Matsuo K and Sano T: Randomized clinical trial of duct-to-mucosa versus invagination pancreaticojejunostomy after pancreatoduodenectomy. Br J Surg 105: 48-57, 2018.

2. Balzano G, Zerbi A, Capretti G, Rocchetti S, Capitanio V and Di Carlo V: Effect of hospital volume on outcome of pancreaticoduodenectomy in Italy. Br J Surg 95: 357-362, 2008.

3. Van der Gaag NA, Harmsen K, Eshuis WJ, Busch OR, van Gulik TM and Gouma DJ: Pancreatoduodenectomy associated complications influence cancer recurrence and time interval to death. Eur J Surg Oncol 40: 551-558, 2014.

4. Van Berge Henegouwen MI, Allema JH, van Gulik TM, Verbeek PC, Obertop H and Gouma DJ: Delayed massive haemorrhage after pancreatic and biliary surgery. Br J Surg 82: 1527-1531, 1995 .

5. Wente MN, Veit JA, Bassi C, Dervenis C, Fingerhut A, Gouma DJ, Izbicki JR, Neoptolemos JP, Padbury RT, Sarr MG, et al: Postpancreatectomy hemorrhage (PPH): An International Study Group of Pancreatic Surgery (ISGPS) definition. Surgery 142: 20-25, 2007.

6. Wente MN, Bassi C, Dervenis C, Fingerhut A, Gouma DJ, Izbicki JR, Neoptolemos JP, Padbury RT, Sarr MG, Traverso LW, et al: Delayed gastric emptying (DGE) after pancreatic surgery: A suggested definition by the International Study Group of Pancreatic Surgery (ISGPS). Surgery 142: 761-768, 2007.

7. Bassi C, Dervenis C, Butturini G, Fingerhut A, Yeo C, Izbicki J, Neoptolemos J, Sarr M, Traverso W and Buchler M; International Study Group on Pancreatic Fistula Definition: Postoperative pancreatic fistula: An international study group (ISGPF) definition. Surgery 138: 8-13, 2005.

8. Alamo JM, Marín LM, Suarez G, Bernal C, Serrano J, Barrera L, Gómez MA, Muntané J and Padillo FJ: Improving outcomes in pancreatic cancer: Key points in perioperative management. World J Gastroenterol 20: 14237-14245, 2014.

9. Braga M, Capretti G, Pecorelli N, Balzano G, Doglioni C, Ariotti R and Di Carlo V: A prognostic score to predict major complications after pancreaticoduodenectomy. Ann Surg 254: 702-708, 2011.

10. Dindo D, Demartines N and Clavien PA: Classification of surgical complications: A new proposal with evaluation in a cohort of 6336 patients and results of a survey. Ann Surg 240: 205-213, 2004

11. DeOliveira ML, Winter JM, Schafer M, Cunningham SC, Cameron JL, Yeo CJ and Clavien PA: Assessment of complications after pancreatic surgery: A novel grading system applied to 633 patients undergoing pancreaticoduodenectomy. Ann Surg 244: 931-939, 2006.

12. Clavien PA, Sanabria JR and Strasberg SM: Proposed classification of complications of surgery with examples of utility in cholecystectomy. Surgery 111: 518-526, 1992. 
13. Zhou J, Yu P, Shi Y, Tang B, Hao Y, Zhao Y and Qian F: Evaluation of Clavien-Dindo classification in patients undergoing total gastrectomy for gastric cancer. Med Oncol 32: 120, 2015.

14. Torrecilla C, Vicéns-Morton AJ, Meza IA, Colom S, Etcheverry B, Vila H and Franco E: Complications of percutaneous nephrolithotomy in the prone position according with modified Clavien-Dindo grading system. Actas Urol Esp 39: 169-174, 2015.

15. Tempero MA, Arnoletti JP, Behrman S, Ben-Josef E, Benson AB III, Berlin JD, Cameron JL, Casper ES, Cohen SJ, Duff M, et al: Pancreatic adenocarcinoma. J Natl Compr Canc Netw 8: 972-1017, 2010.

16. Yeo CJ, Cameron JL, Maher MM, Sauter PK, Zahurak ML, Talamini MA, Lillemoe KD and Pitt HA: A prospective randomized trial of pancreaticogastrostomy versus pancreaticojejunostomy after pancreaticoduodenectomy. Ann Surg 222: 580-592, 1995 .

17. Monteiro E, Sklar MC, Eskander A, de Almeida JR, Shrime M, Gullane P, Irish J, Gilbert R, Brown D, Higgins K, et al: Assessment of the Clavien-Dindo classification system for complications in head and neck surgery. Laryngoscope 124: 2726-2731, 2014.

18. Yoon PD, Chalasani V and Woo HH: Use of Clavien-Dindo classification in reporting and grading complications after urological surgical procedures: Analysis of 2010 to 2012. J Urol 190: 1271-1274, 2013.

19. Panhofer P, Ferenc V, Schütz M, Gleiss A, Dubsky P, Jakesz R, Gnant M and Fitzal F: Standardization of morbidity assessment in breast cancer surgery using the Clavien Dindo Classification. Int J Surg 12: 334-339, 2014.

20. Martins Tde C, Duarte TC, Mosca ER, Pinheiro Cde F, Marçola MA and De-Souza DA: Severe protein malnutrition in a morbidly obese patient after bariatric surgery. Nutrition 31 : 535-538, 2015.
21. Moghadamyeghaneh Z, Hwang G, Hanna MH, Phelan MJ, Carmichael JC, Mills SD, Pigazzi A, Dolich MO and Stamos MJ: Even modest hypoalbuminemia affects outcomes of colorectal surgery patients. Am J Surg 210: 276-284, 2015.

22. Baron TH and Kozarek RA: Preoperative biliary stents in pancreatic cancer-proceed with caution. N Engl J Med 362: 170-172, 2010.

23. Van der Gaag NA, Rauws EA, Van Eijck CH, Bruno MJ, van der Harst E, Kubben FJ, Gerritsen JJ, Greve JW, Gerhards MF, de Hingh IH, et al: Preoperative biliary drainage for cancer of the head of the pancreas. N Engl J Med 362: 129-137, 2010.

24. Kozarek R: Role of preoperative palliation of jaundice in pancreatic cancer. J Hepatobiliary Pancreat Sci 20: 567-572, 2013.

25. LassenK,Coolsen MM,SlimK,CarliF, de Aguilar-NascimentoJE, Schäfer M, Parks RW, Fearon KC, Lobo DN, Demartines N, et al: Guidelines for perioperative care for pancreaticoduodenectomy: Enhanced Recovery After Surgery $\left(\right.$ ERAS $\left.^{\circledR}\right)$ Society recommendations. Clin Nutr 31: 817-830, 2012.

26. Sohn TA, Yeo CJ, Cameron JL, Lillemoe KD, Talamini MA, Hruban RH, Sauter PK, Coleman J, Ord SE, Grochow LB, et al: Should pancreaticoduodenectomy be performed in octogenarians? J Gastrointest Surg 2: 207-216, 1998.

27. Riall TS, Reddy DM, Nealon WH and Goodwin JS: The effect of age on short-term outcomes after pancreatic resection: A population-based study. Ann Surg 248: 459-467, 2008. 